\title{
n-TYPE CADMIUM TELLURIDE SURFACE BARRIER NUCLEAR DETECTORS
}

\author{
A. J. DABROWSKI, J. CHWASZCZEWSKA, J. IWAŃCZYK \\ Institute of Nuclear Research, SLDP 05-400 Swierk, Poland
}

and

\author{
R. TRIBOULET, Y. MARFAING
}

Laboratoire de Magnétisme et de Physique des Solides, 92 Meudon-Bellevue, France

\begin{abstract}
Résumé. - Des cristaux de tellurure de cadmium de haute qualité, préparés par la méthode de fusion de zone en tube scellé, ont été employés pour préparer des détecteurs à barrière de surface en vue de la spectroscopie $X$ ou $\gamma$. Des résolutions en énergie (largeurs à mi-hauteur) de 1,7 et $1,1 \mathrm{keV}$ ont été atteintes pour des photons $\gamma$ de $59,5 \mathrm{keV}(241 \mathrm{Am})$ et X de $5,9 \mathrm{keV}(55 \mathrm{Fe})$, respectivement. On présente également les résultats préliminaires de l'étude de l'effet de la température sur ces performances. Par ailleurs, on a étudié l'influence d'un certain nombre de paramètres sur les propriétés de détection. Les points essentiels d'un modèle théorique établissant l'efficacité de collection des charges et la forme des pics d'absorption totale dans des jonctions à barrière de surface, ayant une épaisseur de zone de charge d'espace donnée, sont présentés.
\end{abstract}

Abstract. - Highly perfect n-type CdTe single crystals grown by the sealed-ingot-zone refining method have been used to fabricate semiconductor surface-barrier detectors for X-and low-energy $\gamma$-ray analysis. An energy resolution of $1.7 \mathrm{keV}$ (FWHM) and $1.1 \mathrm{keV}$ (FWHM) was achieved for $59.5 \mathrm{keV} \gamma$-rays from ${ }^{241} \mathrm{Am}$ and $5.9 \mathrm{keV}$ characteristic $\mathrm{K} \mathrm{X}$-ray line from ${ }^{55 \mathrm{Fe}}$ source, respectively. Preliminary measurements of a temperature dependence of the spectrometric properties of n-type CdTe detectors were also performed. The analysis of the effect of some factors upon spectrometric performance of the detector has been made. Main assumptions of the theoretical model of charge collection efficiency and the shape of the full energy peak for surface-barrier junction with a fixed space charge are presented.

1. Introduction. - The development of cadmium telluride nuclear radiation detectors is an important part of investigations on application of semiconducting materials to ionizing radiation detection [1-4]. At the same time the methods used for the examination of detectors have been found to be applicable to the determination of a number of the properties of starting material, the detector is made of.

This paper reports on cadmium telluride nuclear detectors made of low resistivity n-type $\mathrm{CdTe}$ single crystal. The active region of these detectors is formed by a depletion layer created below the crystal surface as a result of a reverse bias applied to the surface barrier. In view of the small resistivity of the starting material, the thickness of the active region does not exceed $100 \mu \mathrm{m}$ for a detector bias voltage below $200 \mathrm{~V}$.

In these conditions, even at low bias voltages, a high electric field is created. This feature, combined with the observed low reverse currents, provides for good energy resolution for low energy $\gamma$ and $\mathbf{X}$ radiation at room temperature $[5,6]$.

2. Material and detectors. - Cadmium telluride single crystal were obtained from ingots highly purified by the sealed-ingot-zone refining method according to the process described in ref. [7]. The electrical measurements data for several samples are summarized in table I. Some mobility vs. temperature curves are plotted

TABLE I

\begin{tabular}{|c|c|c|c|c|}
\hline $\begin{array}{l}\text { Name } \\
\eta_{300 \mathrm{~K}} \\
\mathrm{~cm}^{-3}\end{array}$ & $1.45 \times 10^{13}$ & $4.95 \times 10^{13}$ & $5.1 \times 10^{13}$ & CTZV 54 \\
\hline $\begin{array}{l}\rho_{300 \mathrm{~K}} \\
\Omega \mathrm{cm}\end{array}$ & 390 & 123 & 130 & 220 \\
\hline $\begin{array}{c}\mu_{300 \mathrm{~K}} \\
\mathrm{~cm}^{2} / \mathrm{V} \mathrm{s}\end{array}$ & 1100 & 1020 & 950 & 930 \\
\hline $\begin{array}{l}\eta_{32 \mathrm{~K}} \\
\mathrm{~cm}^{-3}\end{array}$ & $7.4 \times 10^{12}$ & $1.65 \times 10^{13}$ & $1.65 \times 10^{13}$ & $1.3 \times 10^{13}$ \\
\hline $\begin{array}{l}\rho_{32 \mathrm{~K}} \\
\mathbf{\Omega} \mathrm{cm}\end{array}$ & 8.3 & 3.36 & 2.6 & 5.27 \\
\hline $\begin{array}{c}\mu_{32 \mathrm{~K}} \\
\mathrm{~cm}^{2} / \mathrm{V} \mathrm{s}\end{array}$ & $1.03 \times 10^{5}$ & $1.13 \times 10^{5}$ & $1.46 \times 10^{5}$ & $\times 10^{4}$ \\
\hline
\end{tabular}

in figure 1. The first curve corresponds to one of the purest samples $24 \mathrm{~A} 5$ with $\mu_{32 \mathrm{~K}}=1.46 \times 10^{5} \mathrm{~cm}^{2} / \mathrm{V}$.s. The curves 2, 3 and 4 refer to the samples of decreasing purity, i. e., the samples taken from less pure parts of the ingot. To prepare the detectors, slices of a suitable 


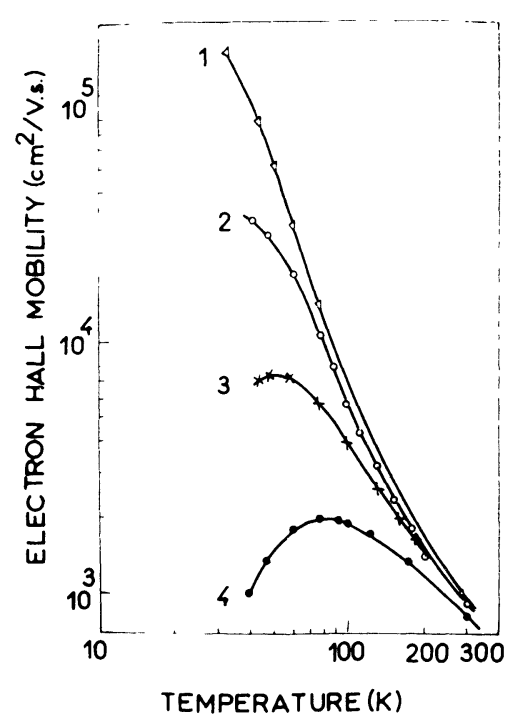

FIG. 1. - Electron mobility vs. temperature for samples cut from the head (1) to the end (4) of vertical zone melted ingots.

thickness were cut from a CdTe ingot, lapped, polished, and carefully cleaned mechanically and chemically in a bromine-methanol solution for 1-2 min., depending on the sample size. After having been removed from the solution, the samples were kept in an inert gas atmosphere. The back contacts were made of indium. The front surfaces of the slices were covered with evaporated $\mathrm{Au}$ dots of a diameter of 1-6 mm and thickness 20-100 $\mu \mathrm{g} / \mathrm{cm}^{2}$. Finally, the slices were mounted in our standard laboratory holders.

3. Electrical characteristics. - To evaluate electrical properties of the prepared devices the I-V curves were measured for the forward and reverse directions over the temperature range $-30^{\circ} \mathrm{C}-+80^{\circ} \mathrm{C}$.

The values of reverse currents at room temperature range between 0.2 and $3 \mathrm{nA}$ for bias voltage values from $30 \mathrm{~V}$ to $100 \mathrm{~V}$ (cf. Fig. 2). Temperature depen-

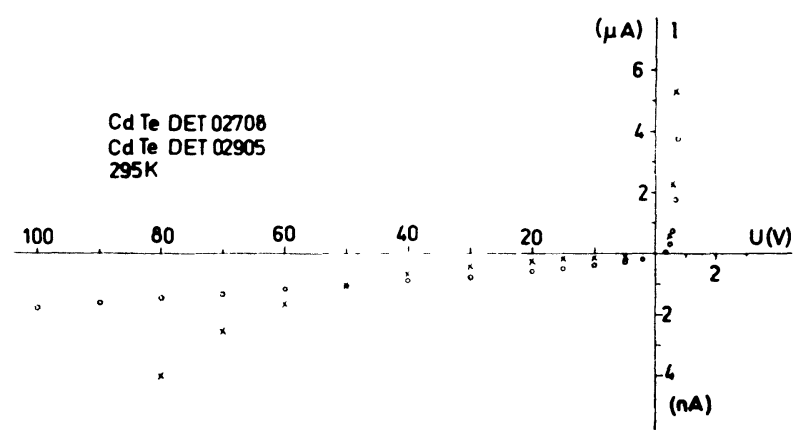

FIG. 2. - Typical I-V characteristics for two CdTe detectors at $295 \mathrm{~K}$.

dence of the reverse currents for several bias voltages is presented in figure 3 . It has been noticed that a $10^{\circ} \mathrm{C}$ temperature change alters the reverse current of the detector by a factor of two.

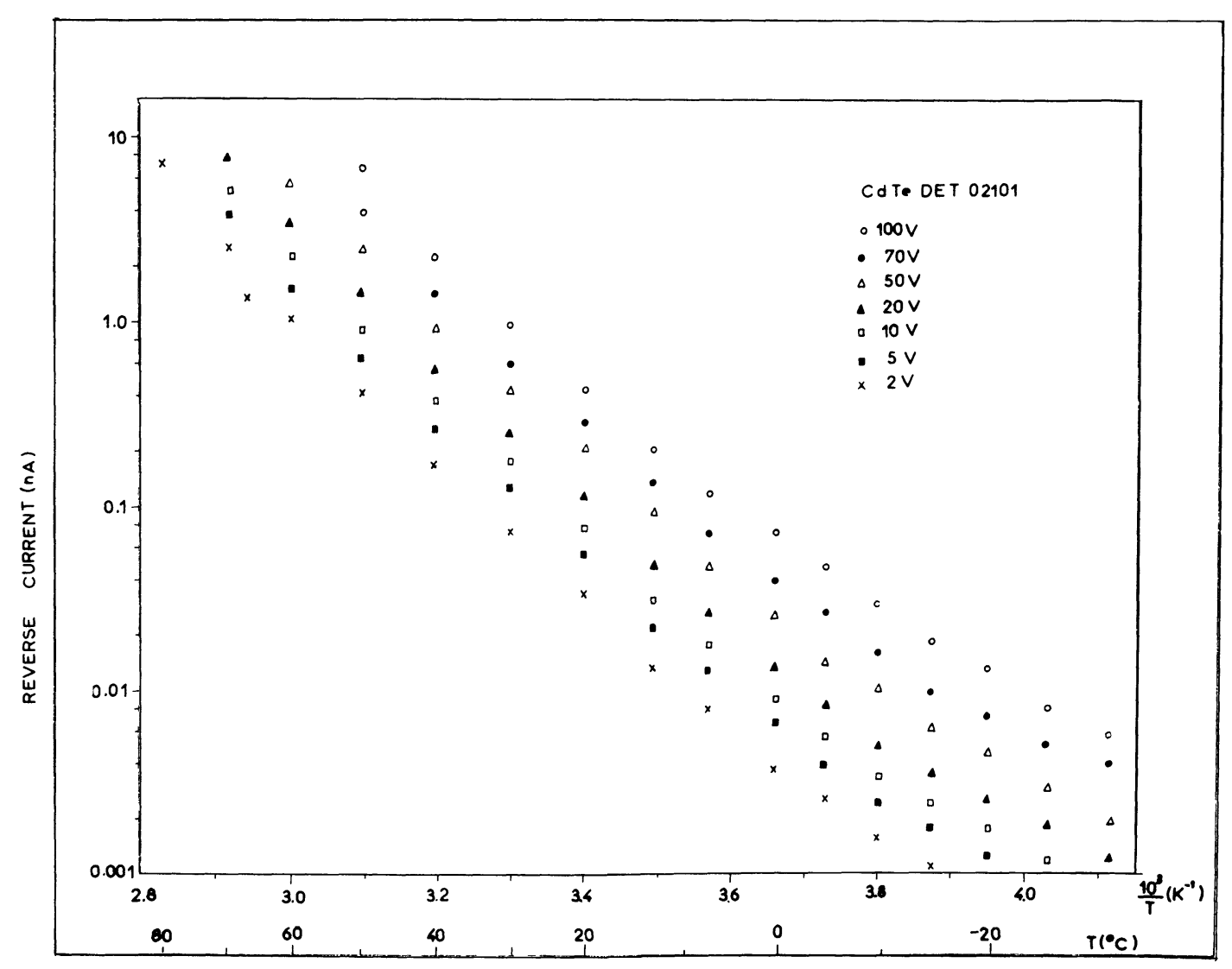

Fig. 3. - Reverse current of CdTe detector vs. temperature measured under various values of detector bias. 
The forward characteristics provide the values of detector resistivity outside the barrier. It appears that in the conditions of the technology used, when the whole process of detector preparation is carried at room temperature, the detector resistivity outside the depletion layer is dominated by the back-contact resistance. Depending on the method of contact preparation this resistance ranges between $10^{3} \Omega$ and $10^{6} \Omega$.

The measurements of the detector capacity as a function of the voltage applied figure 4 show signifi-

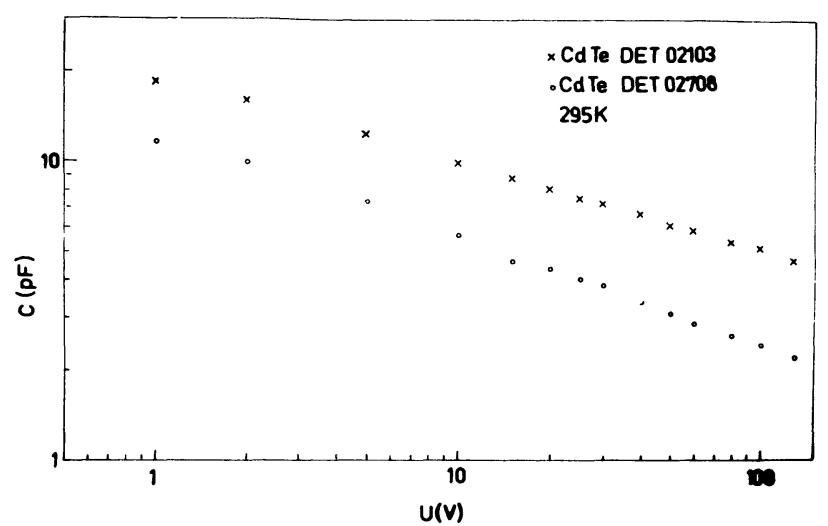

FIG. 4. $-C-V$ characteristics for two CdTe detectors.

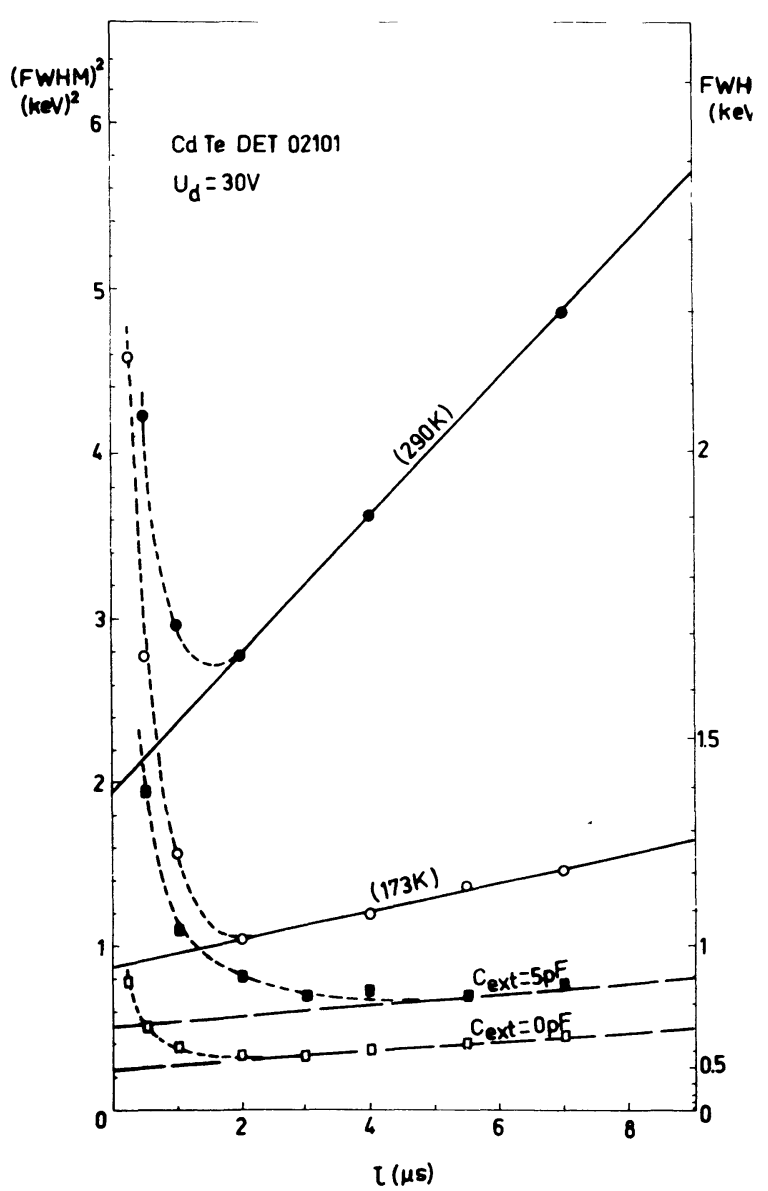

FIG. 5. - Noise as a function of time constant for preamplifier with detector at $290 \mathrm{~K}(\bullet)$, at $173 \mathrm{~K}(\mathrm{O})$, without detector $(\square)$, and with external capacitance $5 \mathrm{pF}(\square)$. cant deviations from the conventional relation $C \sim V^{-0.5}$. In our case this relation, estimated for higher detector bias voltages where the experimental points follow approximately a straight line, is $C \sim V^{-0.3}$. Similar capacity-voltage characteristics for n-type CdTe surface-barrier detectors were reported in ref. [8] and [9].

4. Electronic noise. - An analysis of the noise of the detector-electronics system has been performed. The measurement results are presented in figures 5 and 6 in the form of

$$
\mathrm{FWHM}^{2}=f(\tau) \text { and } \mathrm{FWHM}^{2}=f(1 / \tau)
$$

curves. Such procedure makes it possible to separate parallel and series noise. As it is known [10] the slope on the right-hand side of the minimum of $f(\tau)$ curve is determined by the parallel noise. On the other hand the slope of $f(1 / \tau)$ is proportional to the series noise and a square of the input capacity.

A comparison of the slopes of $f(\tau)$ functions for the system with the detector, without the detector and with a capacity simulating the detector reveals that the investigated detector introduces an additional series noise which depends on frequency as $1 / f$ and $1 / f^{2}$.

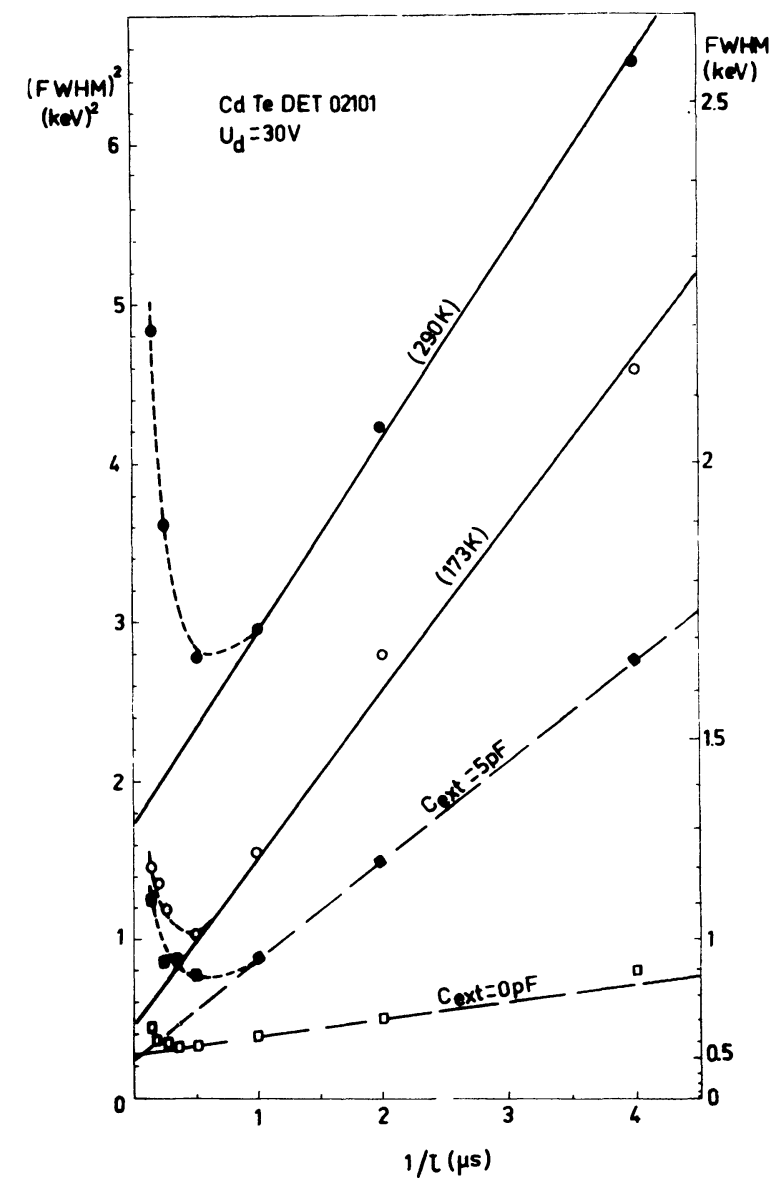

Fig. 6. - Noise as a function of reciprocal time constant $1 / \tau$ for preamplifier with detector at $290 \mathrm{~K}(\circlearrowleft)$, at $173 \mathrm{~K}(\mathrm{O})$, without detector $(\square)$ and with external capacitance $5 \mathrm{pF}(\boldsymbol{\square})$. 
If the detector temperature is lowered to $173 \mathrm{~K}$, i. e. when the detector leakage currents become negligible, the series noise of $1 / f$ type is reduced whereas the white series noise remains approximately unchanged.

It is supposed that this frequency dependent excess noise originates in detector contacts. The proposed equivalent noise circuit which includes the above noise sources is presented in figure 7. Further detailed investi-

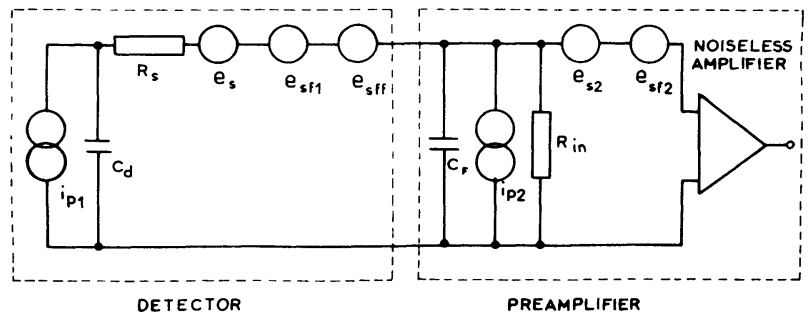

FIG. 7. - Proposed equivalent detector-preamplifier noise circuit.

$i_{p 1}$ parallel white noise of detector leakage current.

es $_{\text {s }}$ series white noise of detector contact.

$\mathbf{e}_{\text {sf } 1}$ series $1 / f$ noise of detector contact.

esff series $1 / f^{2}$ noise of detector contact.

$i_{p 2}$ parallel white noise of transistor leakage current with equivalent sources of white noise generated in parallel resistors (feedback, bias).

$\mathbf{e}_{\mathbf{s} 2}$ series white noise of transistor (thermal noise of FET channel).

$\mathrm{e}_{\mathrm{sf} 2}$ series $1 / f$ noise of transistor (ficker noise of FET).

$C_{\mathrm{d}}$ detector capacitance.

$C_{F}$ transistor capacitance, stray capacitance and feedback capacitance.

$\boldsymbol{R}_{\mathbf{l n}}$ input resistance of preamplifier.

$R_{\mathrm{s}}$ detector contact resistance.

gations of this problem will be aimed at application of the presented measurement method in technological research on the improvement of detector contacts.

5. Charge collection process. - The effect charge trapping on the detector properties related to $\gamma$-ray spectroscopy has been frequently examined in the case of $p$-i-n junction both for germanium and lithiumdrifted silicon detector [11-14] and for CdTe detectors made of semi-insulating material [15-17]. A surfacebarrier junction with a fixed space charge has been used mostly in the spectrometry of charged particles and its application to $\gamma$-and X-ray spectrometry has been considered as impractical. However, the progress achieved in the parameters of n-type CdTe [2,5,6] and n-type GaAs [18-20] detectors made it possible to use them in the spectrometry of low energy gamma and $\mathrm{X}$-radiation. This progress has necessitated the development of a model of charge collection for junctions of this type.

The effect of charge trapping on spectrometric performance of n-type CdTe surface-barrier detector for $\gamma$-rays was recently analysed by us elsewhere [21].
The electric field distribution in n-type CdTe detector has been assumed to be of the form

$$
E(x)=\frac{2 V}{W^{2}} x,
$$

where $V$ is the potential difference expanding the depletion layer of the detector to a thickness $W$.

On the basis of Ramo's theorem extended to the case of the junction with a fixed space charge [22, 23], by using the electric field distribution in the detector (1), and accounting for charge trapping, the expression for charge collection efficiency $\eta(x)$ has been derived in ref. [21].

A typical form of this function is presented in figure 8 . The charge collection efficiency for this type of junc-

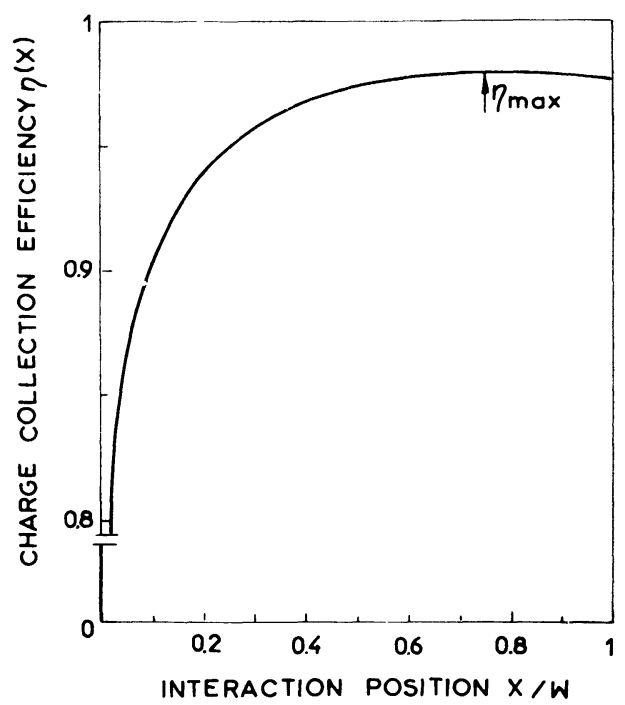

FIG. 8. - Charge collection efficiency as a function of interaction position.

tion vanishes at the positive electrode. This behaviour is to be contrasted with that of p-i-n detectors where the charge collection efficiency is a non-vanishing function over the whole active region.

The charge collection efficiency $\eta(x)$ has been used to calculate the full energy peak. The full energy peak for uniform irradiation of the active volume by monoenergetic $\gamma$-rays has been determined from the expression :

$$
\begin{aligned}
\frac{\mathrm{d} N(E)}{\mathrm{d} E}=\int_{0}^{W} \frac{1}{\sqrt{2 \pi} \sigma} & F(x) \times \\
& \quad \times \exp \left\{-\frac{\left[E-\eta(x) E_{0}\right]^{2}}{2 \sigma^{2}}\right\} \mathrm{d} x
\end{aligned}
$$

where

$\sigma$ accounts for the spread of the number of electron-hole pairs created in ionisation process, statistical distribution of the number of collected carriers and the noise of the detectorelectronics system, 
$E_{0}$ mean amplitude at a $100 \%$ charge collection,

$x \quad$ position of $\gamma$-ray interaction event in the active region of the detector,

$F(x)$ weight factor equal to $1 / W$ for planar detectors,

$\eta(x)$ charge collection efficiency,

$W$ depletion layer depth.

The proposed model (eq. (2)) accounts for symmetrical spectrum broadening related to mean standard deviation $\sigma$ as well as assymetrical broadening weighted towards lower energies and arising from the effect of trapping.

In ref. [21] it was also shown that the product $\mu \tau^{+}$ can be determined for holes and electrons by a comparison of the position and shape of the experimental full energy peak with those calculated theoretically on the assumed model (eq. 2).

Further investigations are aimed at a comparison of the values of $\mu \tau^{+}$obtained by various measurement methods in the same material.

6. Energetic spectra. - Figure 9 presents the spectrum of $X$ - and $\gamma$-rays emitted by ${ }^{241} \mathrm{Am}$ measured using an n-type CdTe detector at room temperature.

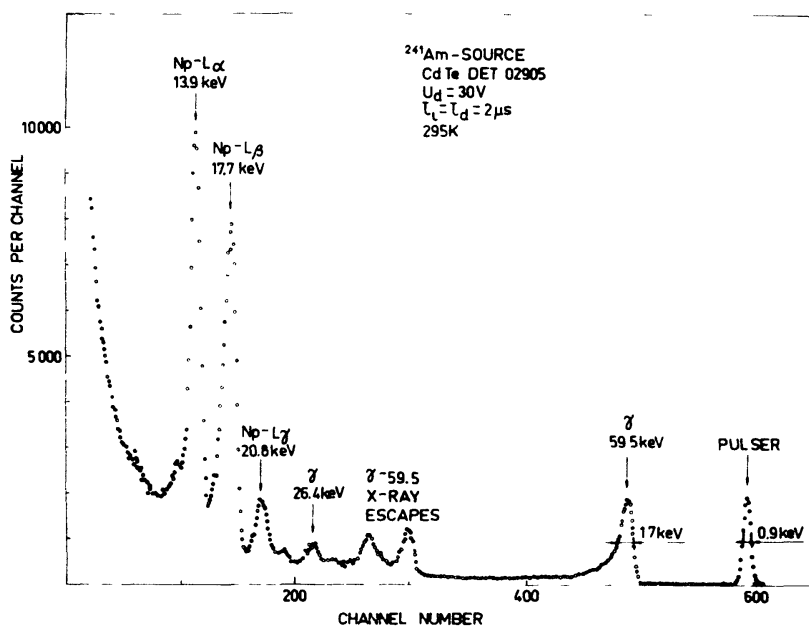

FIG. 9. - X- and $\gamma$-ray spectrum of ${ }^{241} \mathrm{Am}$ obtained using a CdTe surface-barrier detector.

The full energy peak is evidently asymetrical with a broadening towards lower energies. This is connected with the effect of trapping and electron escape out of the depletion region. The resolution for the $59.5 \mathrm{keV}$ gamma-ray peak is $1.7 \mathrm{keV}$ (FWHM). It may be also seen that the $\mathrm{Np}-\mathrm{L}_{\alpha}(13.9 \mathrm{keV}), \mathrm{Np}-\mathrm{L}_{\beta}(17.7 \mathrm{keV})$ and $\mathrm{Np}-\mathrm{L}_{\gamma}(20.8 \mathrm{keV}) \mathrm{X}$-rays are clearly resolved. The position of the peak has been measured for the gammaradiation energy of $59.5 \mathrm{keV}$ by comparision to a $\mathrm{Ge}[\mathrm{Li}]$ spectrometer and found to be over $97.5 \%$ of the full charge collection.

The spectrum of the characteristic X-rays from ${ }^{55} \mathrm{Fe}$ source $(5.9 \mathrm{keV})$ measured with the same detector at room temperature is presented in figure 10 . The energy resolution in this case amounts to $1.1 \mathrm{keV}$ (FWHM).

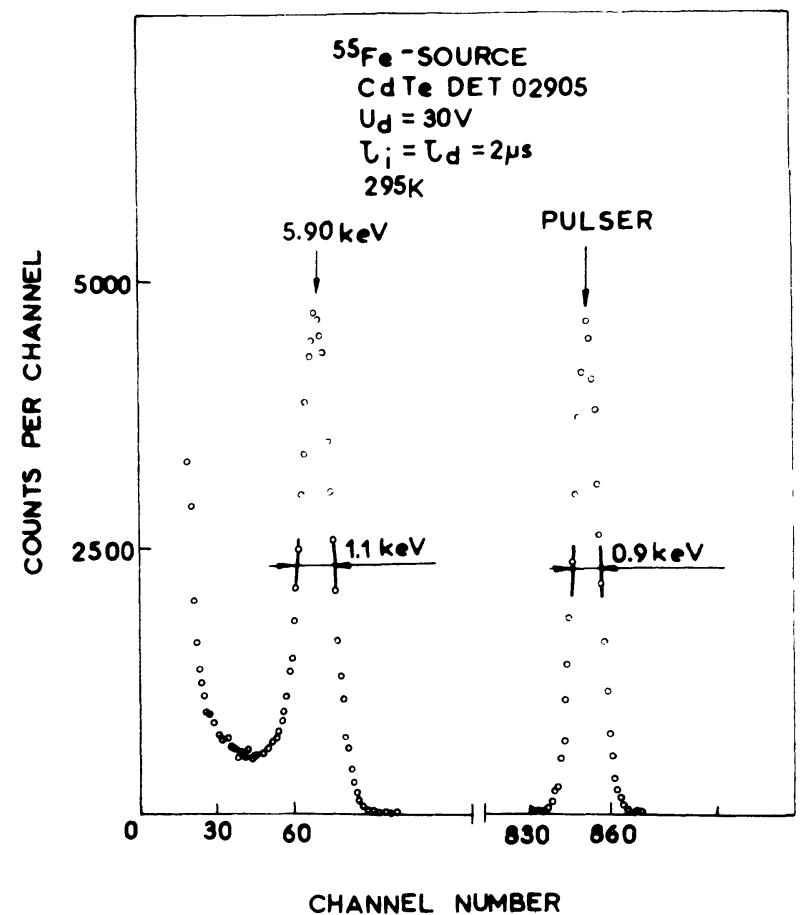

Fig. 10. - Characteristic $\mathrm{K} X$-ray spectrum from $55 \mathrm{Fe}$ source measured using a CdTe surface-barrier detector.

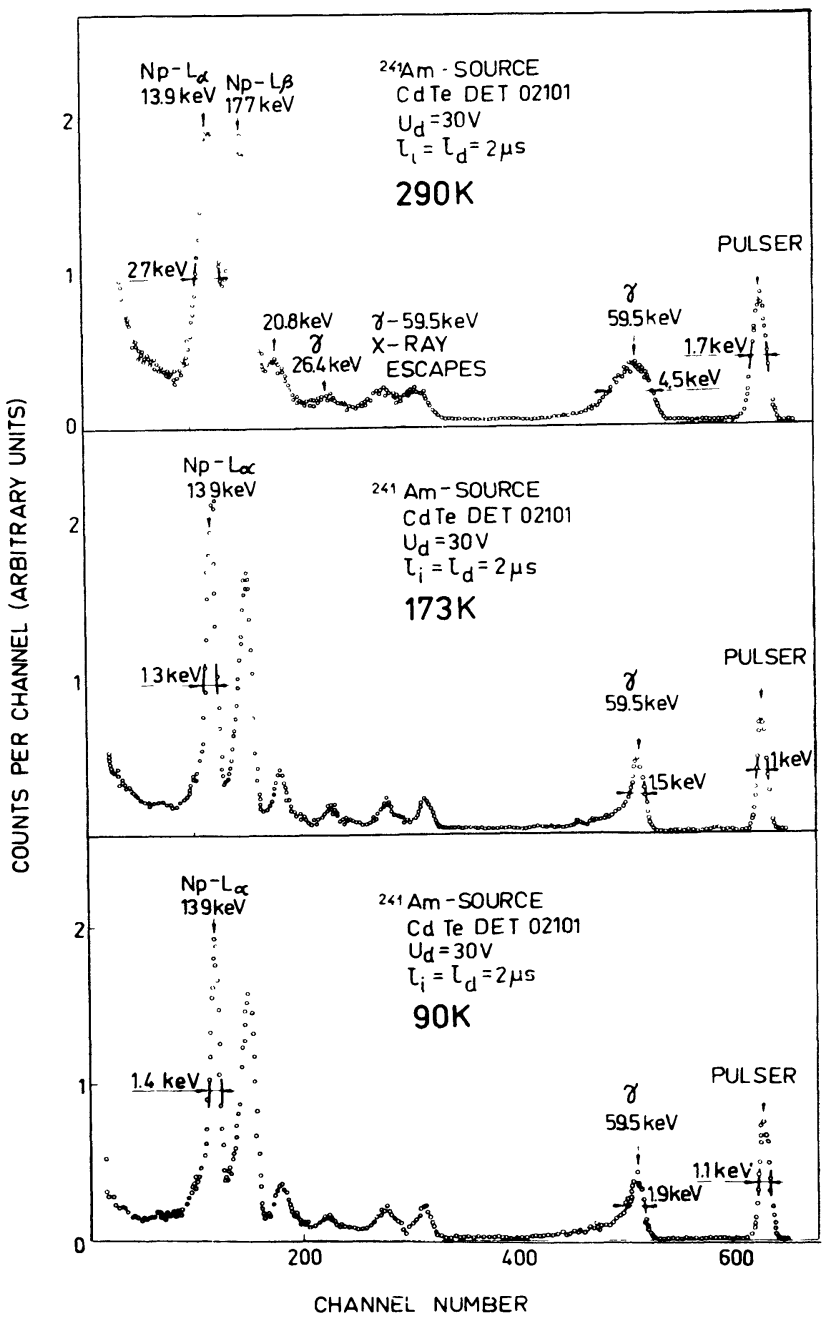

FIG. 11. - X-and $\gamma$-ray spectra of $241 \mathrm{Am}$ measured using a CdTe surface-barrier detector at various temperatures. 
The noise of detector-preamplifier system amounts to $0.9 \mathrm{keV}$ (FWHM), as measured with a pulser. It may be seen from figures 9 and 10 that at low energies the peak are symmetrical and their half widths are close to that of the pulser.

Preliminary measurements of a temperature dependence of the spectrometric properties of n-type CdTe detectors were also performed. They were carried out using a ${ }^{241} \mathrm{Am}$ source and detector No 02101 (cf. Fig. 11). The energy resolution was monitored by the shape of $13.9 \mathrm{keV}$ and $59.5 \mathrm{keV}$ peaks. It has been found that the energy resolution of the low-energy peak varies with temperature as the width of the peak of the pulser. The FWHM for full energy peak exhibits a flat minimum in the vicinity of $170 \mathrm{~K}$. The resolution improves from $4.5 \mathrm{keV}$ at $290 \mathrm{~K}$ to $1.5 \mathrm{keV}$ at $173 \mathrm{~K}$. A considerable improvement of the energy resolution for full energy peak cannot be explained by merely a decrease of the detector-preamplifier noise with lowering temperature. We attribute this effect to an improvement of charge collection in the detector, associate with an increase of $\mu \tau^{+}$at low temperature. On the other hand the tailing towards lower energies and a slight deterioration of the energy resolution at temperatures close to liquid nitrogen temperature should be, in our opinion, attributed to additional shallow trapping levels becoming active at low temperatures.

7. Conclusions. - The paper presents the results obtained for surface-barrier detectors made of n-type CdTe. The analysis of the effect of some factors upon spectrometric performance of the detector has been made. The results of measurements carried out a very low energies $(5.9 \mathrm{keV})$ reveal that the detector resolution is limited by the noise of detector-preamplifier system. This conclusion is valid for room temperature as well as for lower temperature operation. The detector contact seems to be one of more relevent noise sources. The latter feature has not been accounted for in our previous consideretions. The energy resolution at higher energies $(59.5 \mathrm{keV})$ is limited mainly by the trapping effect and the escape of electrons from the active region. A marked decrease of $59.5 \mathrm{keV}$ peak width at lower temperature cannot be accounted for by merely a reduction of the detector-preamplifier noise. The improvement of energy resolution is to be attributed to a better charge collection associated with an increase of the factor $\mu \tau^{+}$at lower temperatures. The paper presents main assumptions of the theoretical model of charge collection efficiency and the shape of the full energy peak for surface-barrier junction with a fixed space charge. The results presented in the paper indicate that semiconductor surface barrier detectors made of n-type CdTe can be successfully used as X-ray and low energy gamma spectrometers operating over the range from room temperature down to liquid nitrogen temperature.

Acknowledgments. - The authors wish to thank Dr M. Sowiński for his support during the work and Dr. W. Szymczyk for helpful discussions. We are grateful to Mr. G. Didier for his skillful assistance in the preparation of the crystals and Mrs. M. I. Walerian for assisting in the fabrication of the detectors.

\section{References}

[1] MAYeR, J. W., in Semiconductor detectors eds. G. Bertolini and A. Coche (North-Holland Publ. Co., Amsterdam) 1968 , ch. 5.

[2] Proc. Intern. Symp. on Cadmium telluride, Strasbourg, France/eds. P. Siffert and A. Cornet ; 1971.

[3] Malm, H. L., Raudorf, T. W., Martini, M. and Zanio, K. R., IEEE Trans. Nucl. NS-20 (1973) 500.

[4] Siffert, P., Gonidec, J. P. and CoRnet, A., Nucl. Instrum. Meth. 115 (1974) 13.

[5] Dabrowski, A. J., Iwańczyk, J. and Triboulet, R., Nucl. Instrum. Meth. 126 (1975) 417.

[6] Dabrowski, A. J., ChwaszczewsKa, J., IwańczyK, J., Triboulet, $\mathrm{R}$. and Marfaing, Y., IEEE Trans. Nucl. Sci. NS-23 (1976) 171.

[7] Triboulet, R. and Marfaing, Y., J. Electrochem. Soc. 120 (1973) 1260.

[8] MaYer, J. W., J. Appl. Phys. 38 (1967) 296.

[9] Cornet, A., Siffert, P., Coche, A. and Triboulet, R., Appl. Phys. Lett. 17 (1970) 432.

[10] RADEKA, V., Int. Symp. on Nuclear Electronics, Versailles, France (1968) 46-1.

[11] Day, R. B., Dearnley, G. and Palms, J. M., IEEE Trans. Nucl. Sci. NS-14 (1967) 487.
[12] Zulliger, H. R. and Aitken, D. W., IEEE Trans. Nucl. Sci. NS-15 (1968) 466.

[13] Trammell, R. and Walter, F. J., Nucl. Instrum. Meth. 76 (1969) 317

[14] McMath, T. A. and Martini, M., Nucl. Instrum. Meth. $86(1970) 245$.

[15] Akutagawa, W. and Zanio, K., J. Appl. Phys. 40 (1969) 3838.

[16] ZANio, K., Nucl. Instrum. Meth. 83 (1970) 288.

[17] BeLl, R. O., Nucl. Instrum. Meth. 93 (1971) 341.

[18] Eberhardt, J. E., Ryan, R. D. and Tavendale, A. J., Nucl. Instrum. Meth. 94 (1971) 463.

[19] Gibbons, P. E. and Howes, J. H., IEEE Trans. Nucl. Sci. NS-19 (1972) 353.

[20] Kobayashi, T., Sugita, T., Koyama, M. and ToKayNAGI, S., IEEE Trans. Nucl. Sci NS-19 (1972) 324.

[21] IwAŃCZYK, J. and DABrowsKI, A. J., to be published in Nucl. Instrum. Meth. 134 (1976).

[22] Cavalleri, G., Fabri, G. and Svelto, V., Nucl. Instrum. Meth. 21 (1963) 177.

[23] Cavalleri, G., Fabri, G. and Svelto, V., Nucl. Instrum. Meth. 92 (1971) 137. 